\title{
The HER Salt Lake media campaign: comparing characteristics and outcomes of clients who make appointments online versus standard scheduling
}

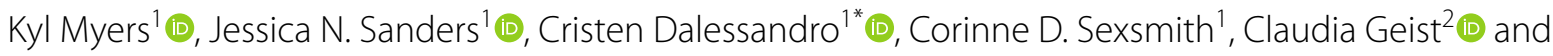
David K. Turok ${ }^{1}$ (D)

\begin{abstract}
Background: Little research has examined how media outreach strategies affect the outcomes of contraceptive initiatives. Thus, this paper assesses the potential impact of an online media campaign introduced during the last six months of a contraceptive initiative study based in Salt Lake City, UT (USA).
\end{abstract}

Methods: During the last six months of the HER Salt Lake Contraceptive Initiative (September 2016-March 2017), we introduced an online media campaign designed to connect potential clients to information about the initiative and a brief (9-item) appointment request form (via HERsaltlake.org). Using linked data from the online form and electronic medical records, we examine differences in demographics, appointment show rates, and contraceptive choices between "online requester" clients who made clinical appointments through the online form $(n=356)$ and "standard requester" clients who made appointments using standard scheduling $(n=3,051)$. We used summary statistics and multivariable regression to compare groups.

Results: The campaign logged 1.7 million impressions and 15,765 clicks on advertisements leading to the campaign website (HERSaltLake.org). Compared to standard requesters, online requesters less frequently reported a past pregnancy and were more likely to be younger, white, and to enroll in the survey arm of the study. Relative to standard requesters and holding covariates constant, online requesters were more likely to select copper IUDs (RRR: 8.14), hormonal IUDs (RRR: 12.36), and implants (RRR: 10.75) over combined hormonal contraceptives (the contraceptive pill, patch, and ring). Uptake of the contraceptive injectable, condoms, and emergency contraception did not differ between groups.

Conclusion: Clients demonstrating engagement with the media campaign had different demographic characteristics and outcomes than those using standard scheduling to arrange care. Online media campaigns can be useful for connecting clients with advertised contraceptive methods and initiatives. However, depending on design strategy, the use of media campaigns might shift the demographics and characteristics of clients who participate in contraceptive initiatives.

\footnotetext{
*Correspondence: Cristen.Dalessandro@hsc.utah.edu

1 Division of Family Planning, Department of Obstetrics and Gynecology, University of Utah School of Medicine, 30 N 1900 E, 2B200, Salt Lake City, UT 84132, USA

Full list of author information is available at the end of the article
} original author(s) and the source, provide a link to the Creative Commons licence, and indicate if changes were made. The images or other third party material in this article are included in the article's Creative Commons licence, unless indicated otherwise in a credit line to the material. If material is not included in the article's Creative Commons licence and your intended use is not permitted by statutory regulation or exceeds the permitted use, you will need to obtain permission directly from the copyright holder. To view a copy of this licence, visit http://creativecommons.org/licenses/by/4.0/. The Creative Commons Public Domain Dedication waiver (http://creativeco mmons.org/publicdomain/zero/1.0/) applies to the data made available in this article, unless otherwise stated in a credit line to the data. 
Trial Registration: Clinicaltrials.gov identifier NCT02734199, Registered 12 April 2016-Retrospectively registered, https://clinicaltrials.gov/ct2/show/NCT02734199.

Keywords: Contraceptives, Media campaign, Contraceptive initiative, LARCs

\section{Background}

In recent years, several states and academic institutions in the U.S. have introduced contraceptive initiatives-or, programs designed to reduce contraceptive cost and access barriers, especially around intrauterine devices (IUDs) and implants. These initiatives have generally been successful at increasing public awareness and uptake of contraceptives and in reducing rates of unintended pregnancies, especially among underserved groups [1-4]. However, the extent to which advertising and recruitment strategies matter for the outcomes of these initiatives remains understudied. While some research has shown that advertising may not make a marked difference in contraceptive uptake more generally [5], we lack information regarding the potential impact of advertising on contraceptive initiatives offering no-cost contraception to prospective clients.

Generally, when it comes to campaigns or initiatives related to health promotion, past research has consistently found that media outreach can be an effective strategy for increasing health-related knowledge among the public and improving health outcomes [6-10]. Research also supports the use of online media strategies in reaching specific, elusive groups, as well as those living in socially conservative contexts [11]. In the past, researchers have found word-of-mouth advertising to be successful in recruiting participants for contraceptive initiatives [12]. However, certain groups of potential clients might not be reached as easily by word-of-mouth. For example, in the United States, research has found that social media and online advertising are especially effective at delivering sexual health and contraceptive information to younger adults (age 18-29), who often look for guidance online [13-16]. Since young adults also have the highest rates of unplanned pregnancy in the United States [17], they are an important potential audience for contraceptive initiatives.

Regarding sexual and reproductive health in particular, past research has found that incorporating media campaigns and online platforms providing contraceptive information (such as Bedsider.org) into research may impact how participants perceive certain methods (especially long-acting reversible contraception, or LARCs) and individuals' contraceptive choices [18-20]. Information on who participates (and who may be left out) as a result of advertising or media outreach efforts, as well as investigating how the use of media may impact client choices, is especially important for informing contraceptive initiative recruitment efforts and in understanding how media messages might matter for clients' contraceptive choices.

In light of the potential for media outreach or advertising to make a difference in the outcomes of contraceptive initiatives, this paper explores the outcomes of an online media campaign introduced during the latter third of the HER Contraceptive Initiative Study (HER Salt Lake) based in Salt Lake City, Utah (USA). As part of the media campaign, advertising directed prospective initiative clients to a simple, nine item online form through the campaign website (HERSatltLake.org) in order to set up appointments for contraceptive care. We compare the clients who made appointments at Planned Parenthood Association of Utah (referred to hereafter as "PPAU") clinics via the online form designed for the media campaign ("online requesters") to clients who did not make their appointments via the HER Salt Lake online form ("standard requesters"). We investigate demographic and characteristic differences between the two groups of clients as well as differences in appointment show rates and method uptake choices. Based on previous research, we hypothesize that the clients reached during our media campaign will be younger and more likely to choose LARC methods than those served during the first two periods of the study, which did not utilize a media campaign. Ultimately, our findings suggest that advertising media campaigns may make a difference when it comes to the demographic characteristics and outcomes of clients participating in a contraceptive initiative.

\section{Methods \\ Design}

HER Salt Lake increased community-wide access to contraceptives over the course of 12 months (March 2016March 2017) by removing contraceptive service costs for eligible clients at four participating PPAU health centers. Contraceptive options that clients could access free of cost included: emergency contraception; contraceptive pills, patches, rings and injections; hormonal and non-hormonal IUDs; contraceptive implants; condoms; and diaphragms. Additionally, clients could switch methods at no cost for up to three years after their first visit. A detailed description of the project and changes in method uptake among clients is reported elsewhere [4]. The Institutional Review Board at the authors' institution 
approved the protocol for the project, including the plans for the media campaign.

Project data collection occurred during three periods: an initial control period, or Period 1 (September 28, 2015 through March 27, 2016); Period 2 (March 28, 2016 through September 25, 2016), which provided increased access and no-cost care; and Period 3 (September 26, 2016 through March 25, 2017), which continued increased access and no-cost care with an added media campaign. During all three periods, clients served at participating clinics who were 18 and over were eligible to enroll in a 3-year prospective survey, and 4,425 enrolled. The survey completed by those enrolled is provided in Additional file 1 ("Enrollment Survey"). In this paper, we describe the online media campaign, engagement, and outcomes including scheduling and method uptake.

During Period 3, the research team partnered with a digital marketing agency to build and launch the campaign, including an official campaign website (HERSaltLake.org) as well as Facebook and Instagram pages. We designed the electronic media campaign to reach the handheld devices of cisgender, nonbinary, and transgender individuals 18- to 34-years-old with potential need for contraceptive services. The research team also increased media presence by participating in local and national press interviews and by writing commentary pieces during the media campaign, which were available online $[21,22]$. Due to the marketing agency's social commitment to the local metropolitan community, they offered a number of services to the HER Salt Lake team at a discounted price. Ultimately, the campaign put $\$ 10,000$ towards the creation and monitoring of HERSaltLake.org and $\$ 20,000$ towards purchasing targeted advertisements and keyword search results, all managed by the marketing agency.

The campaign website had information about available contraceptive methods and linked to Bedsider.org's method finder tool to help interested individuals learn more about different contraceptives [23]. Past research has shown that individuals seeking contraceptive care or information about sexual health view Bedsider.org positively and consider it a trustworthy resource [24, 25]. Individuals visiting Bedsider.org who had an IP address placing them in Utah received a pop-up letting them know about no-cost contraception in their area and a link to the HERSaltLake.org campaign website. The Locations webpage on HERSaltLake.org listed the addresses and phone numbers for PPAU health centers accepting appointments in the county. The Locations page also stated that individuals could walk into any participating health center and receive same-day services for emergency contraception, oral contraceptive pills, patches, rings, injections, and condoms. For those interested in an IUD or implant, the website provided two options: clients could call a scheduling center and make an appointment, or submit a simple nine-question appointment request form located on the webpage. The media strategy also included geo-targeted paid search ads for HERSaltLake.org, which appeared as the top search result when individuals in the county utilized a search engine with specific keywords (see Table 1). Further, we posted advertisements and creative content on the Facebook and Instagram pages linking to HERSaltLake.org (see Fig. 1). Advertisements used modified creative content developed for WhoopsProof.org, a program of Power to Decide (which also operates Bedsider.org), and original content created by the project communications team. All calls to action on advertisements led to the Locations page on HERSaltLake.org.

\section{Sample data}

To assess the reach of the media campaign, we utilized three data sources: media campaign analytics, the online appointment request form accessed through HERSaltLake.org, and Electronic Health Records (EHRs) from PPAU health centers. Media campaign analytic reports served as our first source of data. The digital marketing agency compiled these reports, which provided information on the reach of the media campaign such as the number of impressions and engagements with the campaign (measured by individuals "clicking" on sponsored links).

Table 1 Media campaign search keywords by advertisement group

\begin{tabular}{lll}
\hline IUD group & Implant group & Birth control options group \\
\hline IUD & The Implant & Birth Control \\
Mirena Price & Contraceptive Implant & Best Birth Control \\
Contraceptive IUD & Birth Control Implant & Methods of Birth Control \\
IUD Birth Control & The Implant Contraception & Free Birth Control Utah \\
Copper Intrauterine Device IUD & Birth Control Implant Cost & How to Get Birth Control \\
& & Without Insurance \\
\hline
\end{tabular}




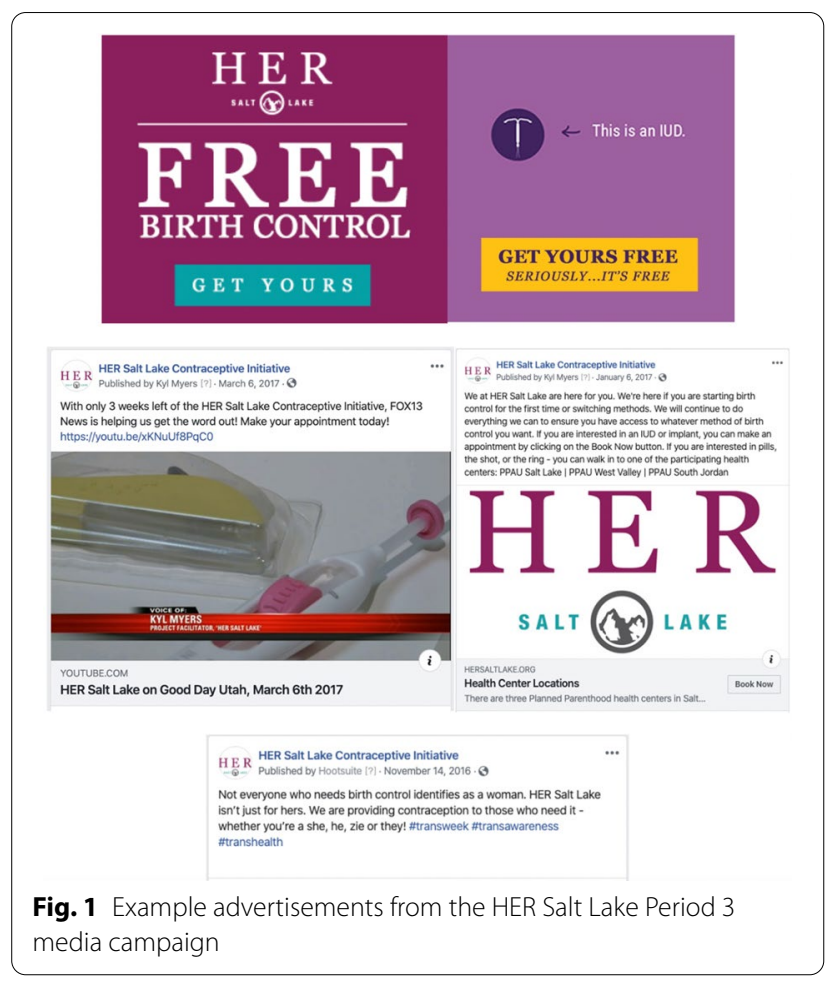

Our second source of data, the online appointment request form, asked for nine pieces of information including name, date of birth, current method of contraception, desired method of contraception, preferred appointment date, preferred appointment time, preferred appointment location, phone number, and email (see Table 2). This differs from the online appointment request form traditionally used by PPAU, which requests the completion of up to 41 information fields. We intentionally limited the number of items to minimize the time needed to complete forms [26].

Clients' online appointment request forms were sent to one, centralized PPAU scheduling e-mail address monitored by PPAU scheduling staff. For potential clients not currently using an IUD or implant (requiring removal) and interested in pills, patches, rings, injections or condoms, staff contacted individuals to inform them that they could walk-in to any participating clinic and be seen without an appointment or schedule an appointment if preferred. Among potential clients currently using an IUD or implant or interested in obtaining an IUD or implant, scheduling staff booked an appointment with a provider. The staff prioritized accommodating preferred appointment request dates, times, and locations of online requesters. It was not uncommon to double book

Table 2 Online appointment request form

\begin{tabular}{|c|c|c|}
\hline Field & Data Format & Rationale \\
\hline Name & Client entered First and Last name & $\begin{array}{l}\text { To set an appointment and establish if the client is a new } \\
\text { or returning patient }\end{array}$ \\
\hline Date of Birth & Client entered MM/DD/YYYY & To verify age eligibility for initiative (16-45 years) \\
\hline Current method of contraception & $\begin{array}{l}\text { Selected current method from drop-down menu: con- } \\
\text { doms; IUD; implant; pill; patch; ring; shot; none; other }\end{array}$ & $\begin{array}{l}\text { To verify eligibility for a walk-in appointment or need for } \\
\text { an appointment with a provider }\end{array}$ \\
\hline Desired method of contraception & $\begin{array}{l}\text { Client selected desired method from drop-down menu: } \\
\text { condoms; IUD; implant; pill; patch; ring; shot; none; } \\
\text { other }\end{array}$ & $\begin{array}{l}\text { To verify eligibility for a walk-in appointment (user- } \\
\text { dependent method) or need for an appointment with } \\
\text { a provider (IUD or implant removal/insertion) and also } \\
\text { to verify eligibility for no-cost contraception through } \\
\text { the contraceptive initiative study i.e. starting or switch- } \\
\text { ing a method }\end{array}$ \\
\hline Preferred appointment date & $\begin{array}{l}\text { Client entered MM/DD/YYYY of preferred appointment } \\
\text { date }\end{array}$ & $\begin{array}{l}\text { Scheduling staff would make every effort to schedule an } \\
\text { appointment for the date preferred by the potential } \\
\text { client. Clinic business days varied by location }\end{array}$ \\
\hline Preferred appointment time & $\begin{array}{l}\text { Client entered time and A.M./P.M. of preferred appoint- } \\
\text { ment }\end{array}$ & $\begin{array}{l}\text { Scheduling staff would make every effort to schedule an } \\
\text { appointment for the time preferred by the potential } \\
\text { client. Clinic business hours varied by location }\end{array}$ \\
\hline Preferred appointment location & $\begin{array}{l}\text { Client selected location from drop down menu of three } \\
\text { clinic options }\end{array}$ & $\begin{array}{l}\text { Scheduling staff would make every effort to schedule an } \\
\text { appointment for the location preferred by the potential } \\
\text { client }\end{array}$ \\
\hline Phone number & Client entered phone number XXX-XXX-XXXX & $\begin{array}{l}\text { Scheduling staff contacted potential clients within } \\
24 \text { h or the next business day to confirm a requested } \\
\text { appointment or to find another time if the requested } \\
\text { appointment was not possible }\end{array}$ \\
\hline E-mail & Client entered e-mail address & $\begin{array}{l}\text { Scheduling staff contacted potential clients within } \\
24 \text { h or the next business day to confirm a requested } \\
\text { appointment or to find another time if the requested } \\
\text { appointment was not possible }\end{array}$ \\
\hline
\end{tabular}


appointments. If unable to accommodate an appointment request (due to preferred appointment being after business hours or no providers in clinic that day), the staff member would contact the potential client and find another satisfactory appointment option. In all cases, PPAU staff members attempted to contact potential clients to confirm appointment requests or discuss options.

Our third source of data comes from PPAU's EHR. PPAU uses NexGen Healthcare (Irvine, CA) to manage client information, including demographics and medical history. We used EHR data to collect data elements for both online requester clients and standard requester clients who sought contraceptive care during Period 3. Data elements included: patient ID, information on if a client's first visit occurred at PPAU during the media campaign and corresponding date, age, race/ethnicity, pregnancy history, whether clients enrolled in the survey portion of the project, location of visit, and birth control outcomes. We also explored whether clients showed up for scheduled appointments and, if applicable, rescheduled appointments. We used EHRs to follow up on whether clients visited one of the clinics after engagement with the media campaign (filling out an appointment request online) and compared online requester clients to eligible standard clients visiting the clinic during the media campaign who did not make their appointments via the online form. Standard requesters used standard scheduling-methods already used by PPAU, including direct calls to clinics and completing the longer online form. Clinical research staff aligned online request forms by patient identifiers with electronic health record data to generate data on demographics and outcomes using REDCap, a secure web platform for designing and managing online databases [27]. Staff checked client IDs to ensure no duplicates. Figure 2 details the participant flow in the context of the larger contraceptive initiative study. Compared to Periods 1 and 2, clients served in Period 3 account for approximately $30 \%$ of the total number of clients served during the entire contraceptive initiative.

\section{Analysis}

We conducted descriptive statistics assessing characteristics of online requesters and standard requesters. First, we used chi-square tests of association to compare the demographic characteristics of the two groups. To conduct our analysis, we excluded participants who initiated care during Periods 1 and 2 of the study so as to assess only those whose initial visit occurred while the media campaign was live. Additionally, in the event that individual clients submitted multiple online request forms, we excluded duplicates in order to count each client only once as an online requester in our analysis. Next, we used multinomial logistic regression to

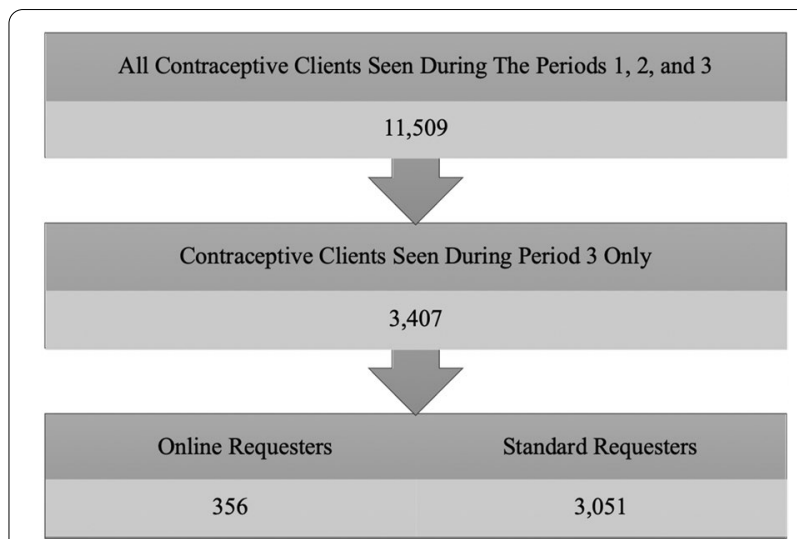

Fig. 2 Participant inclusion/exclusion flow chart in context of larger contraceptive initiative study

compare the contraceptive choices of standard requester and online requester clients in Period 3 (during the media campaign). We also examined information about when potential clients submitted requests and the location of desired appointments. In a last analytic step, we used multinomial logistic regression to explore the types of contraceptive methods selected by those who used the online scheduling system compared to the standard requester clients. We analyzed the combined dataset in Stata version 16 [28].

\section{Results}

From September 28, 2016 to March 25, 2017, there were approximately 1.7 million impressions of the campaign's paid advertisements and 15,765 clicks on advertisements leading to HERSaltLake.org. Ultimately, clients and potential clients submitted 891 online appointment requests through the website. Our form received more than three times the amount of appointment requests compared to PPAU's longer online form (they report receiving approximately 40 forms per month). PPAU staff was able to follow up and establish contact with $95 \%$ of those who filled out an online form from HERSaltLake. org.

Excluding duplicate requests and potential clients who did not respond to PPAU staff follow-up, a total of 610 online requesters either made appointments or were advised by staff to present to the clinic as walk-ins. Approximately $30 \%$ of these potential clients $(n=180)$ never showed up to clinic. After also excluding those who were already enrolled in the study prior to Period 3 and were using the website to make a follow-up appointment, a total of 356 new clients arranged and eventually received care as an outcome of completing the online enrollment form. Of these clients, staff advised 39 to walk in (and did so), while 


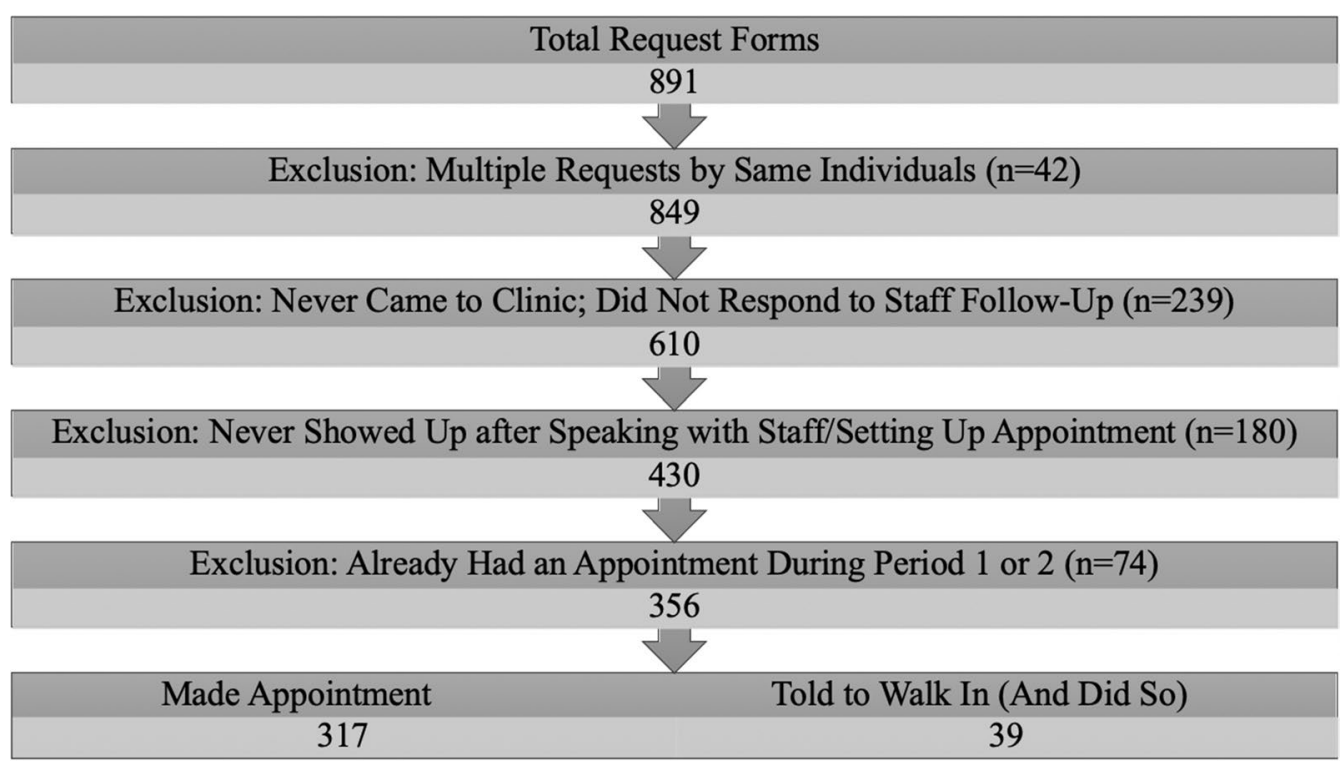

Fig. 3 Sample inclusion/exclusion flow chart-online requesters

317 made appointments. Figure 3 details participant flow. Approximately $72 \%(n=257)$ of the appointment requests for these 356 clients came in between the hours of 9 am and 8 pm, with $89 \%(n=315)$ expressing interest in an IUD or implant. While 51 (or 16\%) of the 356 clients did not show up to their first appointment, these 51 rescheduled appointments and subsequently did show. Half (50\%) of online requester clients were completely new to Planned Parenthood and had never been to a PPAU clinic prior.

In examining the demographics of the online requesters and standard requesters, a greater percentage of online requesters were between 18 and 34 years of age, were more racially white, and were more likely to enroll in the survey portion of the contraceptive initiative study. Online requesters reported less incidence of pregnancy. In addition, online requesters favored certain clinic sites, and choose IUDs or implants more frequently than standard requesters. Table 3 summarizes these demographic differences.

We also performed multinomial logistic regression to assess differences in contraceptive choices among the online requesters and standard requesters. Controlling for other covariates, online requesters more often chose copper IUDs (RRR: 8.14), hormonal IUDs (RRR: 12.36), and implants (RRR: 10.75) compared to the birth control pill, patch, or ring. As shown in Table 4, they were also more likely to choose these methods compared to those in the standard requesters cohort.

\section{Discussion}

We found notable demographic differences between the media campaign requester clients and standard requester clients. Compared to standard requesters, a higher percentage of online requesters were in the initiative's targeted age range (18-34) and subsequently elected to enroll in the survey arm of the contraceptive initiative study. This age difference might be related to previous researchers' finding that younger adults have confidentiality concerns-possibly due to being on their parents' healthcare plans - that drive them to look online in order to investigate or arrange sexual and reproductive health care $[29,30]$. We also posit that the online requesters may have differed from the standard requesters with regard to age due to the tendency of younger adults to use technology to seek health information $[14,15]$.

Online requesters were also more likely to receive IUDs and implants at their clinic appointments. Though this finding differs from previous assessments of media campaigns on LARC uptake [5], the offer of no-cost contraception during the media campaign had a probable role in increasing the likelihood that clients chose LARC methods. For example, the contraceptive initiative study project unfolded in three waves, and those clients in waves 2 and 3 who were offered no-cost contraception were more likely to choose LARC methods than those in the control period. Though they were both offered no-cost contraception, clients were more likely to choose LARC methods overall in Period 3 [4]. At the same time, those with the greatest likelihood of choosing LARC methods were 
Table 3 Demographic characteristics comparing the "online requesters" to the "standard requesters" cohort (September 26, 2016-March 25, 2017)

\begin{tabular}{|c|c|c|c|}
\hline & $\begin{array}{l}\text { Standard requesters } \\
\mathrm{n}(\%)\end{array}$ & $\begin{array}{l}\text { Online requesters } \\
n(\%)\end{array}$ & $p$ \\
\hline \multicolumn{4}{|l|}{ Age } \\
\hline$<18$ & $205(7)$ & $2(1)$ & $<0.001$ \\
\hline $18-24$ & $1431(47)$ & $207(58)$ & \\
\hline $25-34$ & $1035(34)$ & $131(37)$ & \\
\hline $35+$ & $380(12)$ & $16(4)$ & \\
\hline \multicolumn{4}{|l|}{ Race/Ethnicity } \\
\hline White Non-Hispanic & $1889(62)$ & $255(72)$ & $<0.001$ \\
\hline Hispanic & $838(27)$ & $57(16)$ & \\
\hline Other & $324(11)$ & $44(12)$ & \\
\hline \multicolumn{4}{|l|}{ Insurance status } \\
\hline No Insurance & $2082(68)$ & $229(64)$ & 0.135 \\
\hline Insurance & $969(32)$ & $127(36)$ & \\
\hline \multicolumn{4}{|l|}{ Pastpregnancy } \\
\hline No & $1968(65)$ & $275(77)$ & $<0.001$ \\
\hline Yes & $1083(35)$ & $81(23)$ & \\
\hline \multicolumn{4}{|l|}{ HER study enrollment } \\
\hline No & $1924(63)$ & $82(23)$ & $<0.001$ \\
\hline Yes & $1127(37)$ & $274(77)$ & \\
\hline \multicolumn{4}{|l|}{ Clinic location } \\
\hline Metro Health Clinic & $241(8)$ & $17(5)$ & $<0.001$ \\
\hline Salt Lake City Clinic & $991(32)$ & $158(44)$ & \\
\hline South Jordan Clinic & $696(23)$ & $79(22)$ & \\
\hline West Valley Clinic & $1123(37)$ & $102(29)$ & \\
\hline \multicolumn{4}{|l|}{ Birth control outcomes } \\
\hline $\begin{array}{l}\text { Condoms, Dia- } \\
\text { phragm, Emergency } \\
\text { Contraception }\end{array}$ & $216(7)$ & $5(1)$ & $<0.001$ \\
\hline Contraceptive Shot & $425(14)$ & $16(4)$ & \\
\hline $\begin{array}{l}\text { Contraceptive } \\
\text { Implant }\end{array}$ & $283(9)$ & $91(26)$ & \\
\hline Copper IUD & $243(8)$ & $59(17)$ & \\
\hline Hormonal IUD & $434(14)$ & $149(42)$ & \\
\hline None & $177(6)$ & $1(<1)$ & \\
\hline Pill, Patch, or Ring & $1273(42)$ & $35(10)$ & \\
\hline
\end{tabular}

those who made appointments through the media campaign's request form. Differences in LARC uptake could thus be due in part to the availability of Bedsider.org as a resource offered to those completing the online form. Reading information on Bedsider.org may have increased client knowledge about LARCs, potentially piquing interest in LARC methods.

The design of our study makes it difficult to prove that standard requesters were not exposed to the media campaign. It is possible that some clients were exposed to the campaign and chose to request their appointment in a standard fashion anyway. However, those clients who were exposed to the campaign, engaged with it (measured by their completion of the 9-item form), and showed up to their appointments were both demographically different from the standard requester group and had different method choice outcomes. Our findings thus suggest that the importance of advertising strategies on contraceptive initiative campaigns-rather than making no difference-needs further attention. In the future, researchers incorporating media campaigns into their contraceptive initiative projects should note that such an inclusion could have an impact on both on the demographic characteristics of the participant sample and participants' contraceptive choices. The use of media as well as the design of the media campaign itself (such as language featured in the campaign advertisements) can matter for sample demographics.

Also of note, our media campaign efforts did underrepresent some groups of potential clients who may have benefitted from participating in the contraceptive initiative. For example, if the campaign reached prospective clients equally, we would have expected comparable percentages of Hispanic clients and clinic location preference between the two study groups. However, both of these percentages were lower in the online requester group. This drop may be because our advertisements were only in English-a limitation of our study. Spanish advertisements may have changed the potential clients that our online advertisements reached, including more clients from the clinic in our study (Clinic 4) that typically serves the highest number of Spanish-speaking clients. Ads in both English and Spanish may have also better communicated the initiative's commitment to serving Hispanic or bilingual members of the community. Additionally, in order to see the majority of the media campaign activities, potential clients would have to be online in the first place. Further, we did not devise a way to evaluate how (or if) the research team's participation in local and national news or written commentary may have impacted the media campaign. It is possible to determine if these efforts drove some people to HERSaltLake.org where they completed the online form. Further, while we know who made their appointments using the media campaign's online form, we also do not have details from the EHRs concerning which methods of booking appointments that the standard requesters used-phone call, filling out the PPAU form, walking in to make an appointment, and so on. This information would be useful for further exploring, for example, the engagement of standard requesters with the online forms typically used by PPAU. One last limitation of 
Table 4 Multinomial logistic regression of client contraceptive choices

\begin{tabular}{|c|c|c|c|c|c|c|c|c|}
\hline $\begin{array}{l}\text { Condoms, } \\
\text { Diaphragm, EC }\end{array}$ & $\begin{array}{l}\text { Relative Risk } \\
\text { Ratio }\end{array}$ & $95 \% \mathrm{Cl}$ & Copper IUD & $\begin{array}{l}\text { Relative Risk } \\
\text { Ratio }\end{array}$ & $95 \% \mathrm{Cl}$ & $\begin{array}{l}\text { Levonorgestrel } \\
\text { IUD }\end{array}$ & $\begin{array}{l}\text { Relative Risk } \\
\text { Ratio }\end{array}$ & $95 \% \mathrm{Cl}$ \\
\hline \multicolumn{3}{|l|}{ Client group } & \multicolumn{3}{|l|}{ Client group } & \multicolumn{3}{|l|}{ Client group } \\
\hline $\begin{array}{l}\text { Online Request- } \\
\text { ers }\end{array}$ & 1.265 & {$[0.480 ; 3.331]$} & $\begin{array}{l}\text { Online Request- } \\
\text { ers }\end{array}$ & $8.141 \dagger$ & {$[5.155 ; 12.856]$} & $\begin{array}{l}\text { Online Request- } \\
\text { ers }\end{array}$ & $12.364 \dagger$ & {$[8.261 ; 18.503]$} \\
\hline \multicolumn{3}{|l|}{ Age } & \multicolumn{3}{|l|}{ Age } & \multicolumn{3}{|l|}{ Age } \\
\hline$<18$ & 1 & 1 & $<18$ & 1 & 1 & $<18$ & 1 & 1 \\
\hline $18-24$ & $2.633^{*}$ & {$[1.231 ; 5.632]$} & $18-24$ & 3.189 & {$[0.981 ; 10.367]$} & $18-24$ & 0.807 & {$[0.445 ; 1.464]$} \\
\hline $25-34$ & $5.846 \dagger$ & {$[2.711 ; 12.603]$} & $25-34$ & $4.483^{*}$ & {$[1.368 ; 14.695]$} & $25-34$ & 0.984 & {$[0.535 ; 1.811]$} \\
\hline $35+$ & 14.137† & {$[6.152 ; 32.486]$} & $35+$ & $6.655 \neq$ & {$[1.940 ; 22.833]$} & $35+$ & 1.169 & {$[0.589 ; 2.318]$} \\
\hline \multicolumn{3}{|l|}{ Race/ethnicity } & \multicolumn{3}{|l|}{ Race/Ethnicity } & \multicolumn{3}{|l|}{ Racelethnicity } \\
\hline White & 1 & 1 & White & 1 & 1 & White & 1 & 1 \\
\hline Hispanic & 1.047 & {$[0.722 ; 1.519]$} & Hispanic & 0.943 & {$[0.663 ; 1.342]$} & Hispanic & 0.885 & {$[0.663 ; 1.182]$} \\
\hline Other & 0.655 & {$[0.379 ; 1.134]$} & Other & 0.954 & {$[0.630 ; 1.443]$} & Other & 0.789 & {$[0.550 ; 1.131]$} \\
\hline \multicolumn{3}{|l|}{ Insurance } & \multicolumn{3}{|l|}{ Insurance } & \multicolumn{3}{|l|}{ Insurance } \\
\hline Yes & 0.890 & {$[0.645 ; 1.228]$} & Yes & $2.124 \dagger$ & {$[1.597 ; 2.826]$} & Yes & $2.202 \dagger$ & {$[1.730 ; 2.802]$} \\
\hline \multicolumn{3}{|l|}{ Ever been pregnant } & \multicolumn{3}{|c|}{ Ever been pregnant } & \multicolumn{3}{|c|}{ Ever been pregnant } \\
\hline Yes & $0.342 \dagger$ & {$[0.226 ; 0.516]$} & Yes & $1.643 \neq$ & {$[1.194 ; 2.259]$} & Yes & $1.952 \dagger$ & {$[1.495 ; 2.548]$} \\
\hline \multicolumn{3}{|l|}{ Clinic Location } & \multicolumn{3}{|l|}{ Clinic location } & \multicolumn{3}{|l|}{ Clinic location } \\
\hline clinic 1 & 1 & 1 & Clinic 1 & 1 & 1 & Clinic 1 & 1 & 1 \\
\hline Clinic 2 & 1.254 & {$[0.368 ; 4.268]$} & Clinic 2 & $0.216 \dagger$ & {$[0.129 ; 0.363]$} & Clinic 2 & $0.094 \dagger$ & {$[0.0605 ; 0.147]$} \\
\hline Clinic 3 & 1.816 & {$[0.532 ; 6.199]$} & Clinic 3 & $0.123 t$ & {$[0.070 ; 0.215]$} & Clinic 3 & $0.087 \dagger$ & {$[0.055 ; 0.138]$} \\
\hline Clinic 4 & 1.364 & {$[0.402 ; 4.628]$} & Clinic 4 & $0.155+$ & {$[0.0916 ; 0.263]$} & Clinic 4 & $0.099+$ & {$[0.064 ; 0.154]$} \\
\hline \multicolumn{3}{|l|}{ Study enrollment? } & \multicolumn{3}{|l|}{ Study enrollment? } & \multicolumn{3}{|l|}{ Study enrollment? } \\
\hline Yes & $0.163 t$ & {$[0.097 ; 0.274]$} & Yes & $2.518 t$ & {$[1.900 ; 3.338]$} & Yes & $3.878+$ & {$[3.043 ; 4.941]$} \\
\hline $\begin{array}{l}\text { Contraceptive } \\
\text { injectable }\end{array}$ & $\begin{array}{l}\text { Relative risk } \\
\text { ratio }\end{array}$ & $95 \% \mathrm{Cl}$ & $\begin{array}{l}\text { Contraceptive } \\
\text { implant }\end{array}$ & $\begin{array}{l}\text { Relative risk } \\
\text { ratio }\end{array}$ & $95 \% \mathrm{Cl}$ & $\begin{array}{l}\text { None or missing } \\
\text { methods }\end{array}$ & $\begin{array}{l}\text { Relative risk } \\
\text { ratio }\end{array}$ & $95 \% \mathrm{Cl}$ \\
\hline \multicolumn{3}{|l|}{ Client group } & Client group & & & Client group & & \\
\hline $\begin{array}{l}\text { Online request- } \\
\text { ers }\end{array}$ & 1.630 & {$[0.885 ; 3.002]$} & $\begin{array}{l}\text { Online request- } \\
\text { ers }\end{array}$ & $10.753+$ & {$[6.974 ; 16.579]$} & $\begin{array}{l}\text { Online request- } \\
\text { ers }\end{array}$ & 0.368 & {$[0.050 ; 2.733]$} \\
\hline Age & & & Age & & & Age & & \\
\hline$<18$ & 1 & 1 & $<18$ & 1 & 1 & $<18$ & 1 & 1 \\
\hline $18-24$ & $0.536 \neq$ & {$[0.372 ; 0.771]$} & $18-24$ & $3.586^{*}$ & {$[1.103 ; 11.659]$} & $18-24$ & $13.457^{*}$ & {$[1.836 ; 98.648]$} \\
\hline $25-34$ & $0.350 \dagger$ & {$[0.231 ; 0.531]$} & $25-34$ & 2.376 & {$[0.719 ; 7.857]$} & $25-34$ & $28.735 \neq$ & {$[3.911 ; 211.129]$} \\
\hline $35+$ & $0.415 \ddagger$ & {$[0.247 ; 0.697]$} & $35+$ & 1.999 & {$[0.565 ; 7.070]$} & $35+$ & $83.972 \dagger$ & {$[11.210 ; 628.996]$} \\
\hline Race/ethnicity & & & Racelethnicity & & & Race/ethnicity & & \\
\hline White & 1 & 1 & White & 1 & 1 & White & 1 & 1 \\
\hline Hispanic & $1.341 *$ & {$[1.032 ; 1.743]$} & Hispanic & $2.246 t$ & {$[1.670 ; 3.021]$} & Hispanic & 0.897 & {$[0.597 ; 1.348]$} \\
\hline Other & 0.995 & {$[0.685 ; 1.445]$} & Other & 1.167 & {$[0.778 ; 1.753]$} & Other & 0.801 & {$[0.457 ; 1.405]$} \\
\hline Insurance & & & Insurance & & & Insurance & & \\
\hline Yes & 0.809 & {$[0.622 ; 1.051]$} & Yes & $2.083 \dagger$ & {$[1.573 ; 2.757]$} & Yes & 0.867 & {$[0.602 ; 1.248]$} \\
\hline Ever been pregnan & & & Ever been pregnan & & & Ever been pregnan & & \\
\hline Yes & $1.791 \dagger$ & {$[1.354 ; 2.369]$} & Yes & $2.498 \dagger$ & {$[1.852 ; 3.371]$} & Yes & 0.855 & {$[0.575 ; 1.273]$} \\
\hline Clinic location & & & Clinic location & & & Clinic location & & \\
\hline Clinic 1 & 1 & 1 & Clinic 1 & 1 & 1 & Clinic 1 & 1 & 1 \\
\hline Clinic 2 & 1.148 & {$[0.532 ; 2.477]$} & Clinic 2 & $0.214 \dagger$ & {$[0.125 ; 0.365]$} & Clinic 2 & 0.553 & {$[0.226 ; 1.353]$} \\
\hline Clinic 3 & 1.330 & {$[0.613 ; 2.890]$} & Clinic 3 & $0.161 \dagger$ & {$[0.092 ; 0.283]$} & Clinic 3 & 0.574 & {$[0.230 ; 1.428]$} \\
\hline Clinic 4 & 1.766 & {$[0.828 ; 3.770]$} & Clinic 4 & $0.340 \dagger$ & {$[0.204 ; 0.570]$} & Clinic 4 & 0.703 & {$[0.293 ; 1.689]$} \\
\hline Study enrollment? & & & Study enrollment? & & & Study enrollment? & & \\
\hline Yes & 1.066 & {$[0.828 ; 1.373]$} & Yes & $4.798+$ & {$[3.631 ; 6.339]$} & Yes & $0.088 t$ & {$[0.041 ; 0.190]$} \\
\hline
\end{tabular}


our study is that the standard requesters group is larger than the online requester group. Ideally, these groups would have been more comparable in size.

As far as the utility of our media campaign and form for attracting potential clients to the clinics to receive care, we found mixed results. Approximately 30\% $(\mathrm{n}=180)$ never showed up to clinic. This percentage is the same as PPAU's no-show percentage; thus, our form did not improve no-show rates. However, an additional $16 \%$ of clients who eventually did show to an appointment missed their first scheduled appointment. Thus, we would suggest that contraceptive initiatives adopting an online form similar to ours might consider double booking clients initially.

Regarding the importance of our study to the general health communication literature, we reaffirm previous research arguing that media strategies can be useful for getting sexual health information across to certain groups of clients [11]. We also confirm that the use of media seems to reach those in younger cohorts especially, although there can be downsides to this. For instance, in research related to sexual health and other health concerns, it may lead to younger adults being over-represented in samples. Our study also raises questions about the significance of how media messages aimed at recruitment are constructed, since we observed fewer Hispanic participants in Period 3.

Overall, our study provides a much-needed assessment of how an advertising campaign might influence the demographics of clients who participate in contraceptive initiatives. Our media campaign also successfully attracted new clients who had never received care at a PPAU clinic before. Our findings show that while campaigns are a useful way to spread information about contraceptive initiatives and studies, care must be taken during the design stage to ensure that the advertising reaches the appropriate audiences and that design strategies are consistent with an initiative's goals.

\section{Conclusion}

Online media campaigns can be useful for connecting clients with advertised contraceptive methods and initiatives. However, depending on design strategy, the use of media campaigns might shift the demographics and characteristics of clients who participate in contraceptive initiatives. Our research suggests that media advertising campaigns can be useful to contraceptive initiatives, though researchers must be aware that advertising strategies may impact both participant demographics and outcomes in contraceptive initiative studies.
Abbreviations

EHR: Electronic health records; HER Salt Lake: HER Salt Lake Contraceptive Initiative; IUD: Intrauterine device; LARC: Long-acting reversible contraception; PPAU: Planned Parenthood Association of Utah; RRR: Relative Risk Ratio.

\section{Supplementary Information}

The online version contains supplementary material available at https://doi. org/10.1186/s12905-021-01256-x.

Additional file 1. Enrollment Survey.

\section{Acknowledgements}

We would like to thank all the participants and personnel involved in making this study possible. We would also like to thank the HER Salt Lake Data Advisory Committee for feedback on earlier drafts of this paper.

\section{Authors' contributions}

DKT was responsible for study design and oversight. CS contributed study coordination and data management. KM and CD composed the manuscript and prepared it for publication. CG and JNS conducted data cleaning and analysis. CD and KM contributed additional data analysis. All authors participated in the revision of the final manuscript and approved the final version.

\section{Funding}

This project is funded by the Society of Family Planning Research Fund, the William and Flora Hewlett Foundation, and an anonymous foundation. The following companies contributed contraceptive products for the project: Bayer Women's Healthcare, Merck \& Co. Inc., and Teva Pharmaceuticals. Use of REDCap provided by Eunice Kennedy Shriver National Institute of Child Health and Development grant (8UL1TR000105 (formerly UL1RR025764) NCATS/NIH). Team members receive support from the Eunice Kennedy Shriver National Institute of Child Health \& Human Development and the Office of Research on Women's Health of the National Institute of Health, JNS via Award Number K12HD085852 and DKT via K24HD087436. The University of Utah Department of Obstetrics and Gynecology Division of Family Planning receives research funding from Bayer Women's Health Care, Cooper Surgical, Medicines 360, Merck \& Co. Inc., and Sebela Pharmaceuticals. The content is solely the responsibility of the authors and does not represent the official view of any of the funding agencies or participating institutions, including the National Institutes of Health, the University of Utah, or Planned Parenthood Federation of America, Inc.

\section{Availability of data and materials}

The datasets used and/or analyzed during the current study are available from the corresponding author on reasonable request.

\section{Declarations}

Ethics approval and consent to participate

Our research was approved by the University of Utah's Institutional Review Board on 08/08/2013 (IRB \#65794). Participants who formally enrolled in the survey arm of the study provided written informed consent. Those under 18 were not eligible to enroll in the survey portion of the study and thus parental consent is not applicable. The Planned Parenthood Association of Utah granted permission to the HER Salt Lake study personnel for the use of the electronic medical records information.

\section{Consent for publication}

Not applicable.

\section{Competing interests}

The last author (DKT) serves as a consultant for Sebela Pharmaceuticals. The other authors report no conflicts of interest.

\footnotetext{
Author details

${ }^{1}$ Division of Family Planning, Department of Obstetrics and Gynecology, University of Utah School of Medicine, 30 N 1900 E, 2B200, Salt Lake City,
} 
UT 84132, USA. ${ }^{2}$ Department of Sociology and Division of Gender Studies, University of Utah, Salt Lake City, USA.

Received: 31 July 2020 Accepted: 8 March 2021

Published online: 23 March 2021

\section{References}

1. Secura GM, Allsworth JE, Madden T, Mullersman JL, Peipert JF. The contraceptive $\mathrm{CHOICE}$ project: reducing barriers to long-acting reversible contraception. Am J Obstet Gynecol. 2010;203(115):e1-7.

2. Ricketts S, Klingler G, Schwalberg R. Game change in Colorado: widespread use of long-acting reversible contraceptives and rapid decline in births among young, low-income women. Perspect Sex Reprod Health. 2014;46:125-42.

3. McNicholas C, Madden T, Secura G, Peipert JF. The contraceptive CHOICE project round up: what we did and what we learned. Clin Obstet Gynecol. 2014;57:635-43.

4. Sanders JN, Myers K, Gawron LM, Simmons RG, Turok DK. Contraceptive method use during the community-wide HER Salt Lake contraceptive initiative. Am J Public Health. 2018;108:550-6.

5. Byker T, Myers C, Graff M. Can a social media campaign increase the use of long-acting reversible contraception? Evidence from a cluster randomized control trial using Facebook. Contraception. 2019;100:116-22.

6. LaCroix JM, Snyder LB, Huedo-Medina TB, Johnson BT. Effectiveness of mass media interventions for HIV prevention, 1986-2013: a meta-analysis. J Acquir Immune Defic Syndr. 2014;66:S329-40.

7. Snyder LB, Hamilton MA, Mitchell EW, Kiwanuka-Tondo J, Fleming-Milici F, Proctor D. A meta-analysis of the effect of mediated health communication campaigns on behavior change in the United States. J Health Commun. 2004;9(Suppl 1):71-96.

8. Whitaker AK, Terplan M, Gold MA, Johnson LM, Creinin MD, Harwood B. Effect of a brief educational intervention on the attitudes of young women towards the intrauterine device. J Pediatr Adolesc Gynecol. 2010;23(2):116-20.

9. Quattrin R, Filiputti E, Brusaferro S. Health promotion campaigns and mass media: looking for evidence. Primary Health Care. 2015;5(1):1-7.

10. Sundstrom B, DeMaria AL, Meier S, Jones A, Moxley GE. "It makes you rethink your choice of the pill": theory-based formative research to design a contraceptive choice campaign. J Health Commun. 2015:20(11):1346-54.

11. Khawaja Z, Ali KI, Khan S. Using Facebook for sexual health social marketing in conservative Asian countries: a systematic examination. J Health Commun. 2017;22(2):111-23.

12. Spain JE, Peipert JF, Madden T, Allsworth JE, Secura GM. The contraceptive CHOICE project: recruiting women at highest risk for unintended pregnancy and sexually transmitted infection. J Womens Health (Larchmt). 2010;19:2233-8

13. Stevens R, Gilliard-Matthews S, Dunaev J, Todhunter-Reid A, Brawner B, Stewart J. Social media use and sexual risk reduction behavior among minority youth: seeking safe sex information. Nurs Res. 2017;66:368-77.

14. Bull SS, Levine DK, Black SR, Schmiege SJ, Santelli J. Social media-delivered sexual health intervention: a cluster randomized controlled trial. Am J Prev Med. 2012;43:467-74.
15. Zimmerman RS, Palmgreen PM, Noar SM, Lustria MLA, Lu H-Y, Lee HM. Effects of a televised two-city safer sex mass media campaign targeting high-sensation-seeking and impulsive-decision-making young adults. Health Educ Behav. 2007;34:810-26.

16. Moreno MA, Grant A, Kacvinsky L, Moreno P, Fleming M. Older adolescents' views regarding participation in Facebook research. J Adolesc Health. 2012;51:439-44.

17. Finer $L B, Z$ Zolna MR. Declines in unintended pregnancy in the United States, 2008-2011. N Engl J Med. 2016;374:843-52.

18. Sundstrom B, Billings D, Smith E, Ferrara M, Albert B, Suellentrop K. Evaluating the Whoops Proof S.C. campaign: a pair-matched group pretest-posttest quasi-experimental study. Matern Child Health J. 2019;23(8):1036-47.

19. Antonishak J, Kaye K, Swiader L. Impact of an online birth control support network on unintended pregnancy. Soc Mark Q. 2015;21 (1):23-36.

20. Thiel de Bocanegra H, Bradsberry M, Lewis C, Maguire F. Do Bedsider family planning mobile text message and e-mail reminders increase kept appointments and contraceptive coverage? Womens Health Issues. 2017;27(4):420-5.

21. Myers, K. What effects can free contraception have on people's lives? This Utah program aims to find out. 2016. https://rewire.news/article/2016/ 11/11/free-contraception-utah-program/. Accessed 2 July 2020.

22. HER Salt Lake. HER Salt Lake in the news. http://www.hersaltlake.org/inthe-news (2020). Accessed 16 July 2020.

23. Bedsider.org. Birth control methods. https://www.bedsider.org/methods (2020). Accessed 2 July 2020.

24. Giho Y, Jones KA, Dick RN, et al. Feasibility and acceptability of using a web-based contraceptive support tool in a university health clinic. J Am Coll Health. 2020;68(4):336-40.

25. Gressel GM, Lundsberg LS, Illuzzi JL, et al. Patient and provider perspectives on Bedsider.org, an online contraceptive information tool, in a low income, racially diverse clinic population. Contraception. 2014;90(6):588-93.

26. Galloway C. Blink and they're gone: PR and the battle of attention. Public Relat Rev. 2017:43:969-77.

27. Vanderbilt University. REDCap. https://projectredcap.org (2019).

28. Stata Corp. Stata (Version 16). College Station, TX: Stata Corp; 2019.

29. U.S. Department of Health and Human Services. Young adult health care. https://www.hhs.gov/healthcare/about-the-aca/young-adult-coverage/ index.html (2017). Accessed 16 July 2020.

30. Fuentes L, Ingerick M, Jones R, Lindberg L. Adolescents' and young adults' reports of barriers to confidential health care and receipt of contraceptive services. J Adolesc Health. 2018;62:36-43.

\section{Publisher's Note}

Springer Nature remains neutral with regard to jurisdictional claims in published maps and institutional affiliations.

\footnotetext{
Ready to submit your research? Choose BMC and benefit from:

- fast, convenient online submission

- thorough peer review by experienced researchers in your field

- rapid publication on acceptance

- support for research data, including large and complex data types

- gold Open Access which fosters wider collaboration and increased citations

- maximum visibility for your research: over $100 \mathrm{M}$ website views per year
}

At BMC, research is always in progress.

Learn more biomedcentral.com/submissions 